\title{
BMJ Open Knowledge and attitude of health extension workers regarding mental health problems in Jimma Zone, Ethiopia: a cross-sectional study
}

\author{
Yonas Tesfaye (D) , ${ }^{1}$ Zewdie Birhanu, ${ }^{2}$ Liyew Agenagnew, ${ }^{1}$ Susan Anand, ${ }^{3}$ \\ Kiddus Yitbarek (D) , ${ }^{4}$ Gutema Ahmed, ${ }^{1}$ Masrie Getnet, ${ }^{5}$ Gudina Terefe Tucho ${ }^{6}$
}

To cite: Tesfaye Y, Birhanu Z, Agenagnew L, et al. Knowledge and attitude of health extension workers regarding mental health problems in Jimma Zone, Ethiopia: a crosssectional study. BMJ Open 2022;12:e48381. doi:10.1136/ bmjopen-2020-048381

- Prepublication history for this paper is available online. To view these files, please visit the journal online (http://dx.doi org/10.1136/bmjopen-2020048381).

Received 30 December 2020 Accepted 19 January 2022

Check for updates

(c) Author(s) (or their employer(s)) 2022. Re-use permitted under CC BY-NC. No commercial re-use. See rights and permissions. Published by BMJ.

For numbered affiliations see end of article.

Correspondence to

Yonas Tesfaye;

yonastesfaye71@yahoo.com

\section{ABSTRACT}

Objective Health extension workers' (HEWs') knowledge and attitude regarding mental health problems are vital for integrating mental healthcare into primary healthcare services. However, information in this context is scarce in Ethiopia. So, this study aimed to assess HEWs' knowledge and attitude towards mental health problems in Jimma, Ethiopia.

Design A cross-sectional study.

Setting Five districts in Jimma Zone, Ethiopia, 2020.

Participants A total of 259 HEWs working in selected five districts were included in the study.

Outcome The knowledge and attitude status of HEWs towards mental health problems.

Results Nearly half of the respondents had inadequate knowledge $(122,47.1 \%)$ and an unfavourable attitude (125, 48.3\%). Most (139, 53.7\%) described mental illness as due to evil spirits' possession. Almost all (240, 92.7\%) of the respondents reported talking or laughing alone as a manifestation of mental illness. Almost two-thirds (157, $60.6 \%$ ) of the respondents reported people with mental illness are dangerous. About a quarter $(63,24.3 \%)$ of the participants stated witch doctors should manage mental illnesses.

Conclusions A significant proportion of the study respondents had poor knowledge and attitude towards mental health problems. Short-term and long-term mental health training is needed to improve their perception level and to provide effective community mental health services.

\section{INTRODUCTION}

Psychiatric disorders are the major burden of disease worldwide, ${ }^{1}$ yet the lack of mental health services in resource-poor settings is striking. ${ }^{2}$ At present, only $1 \%$ of individuals with mental illnesses in rural Ethiopia access the necessary services and are adherent to mental health treatment. ${ }^{34}$

The primary strategy to narrow this treatment gap is integrating mental healthcare into primary healthcare (PHC). An essential first step in delivering integrated care is to evaluate the community healthcare workers' mental health knowledge and attitude. ${ }^{56}$
Strengths and limitations of this study

- The study is the first of its kind regarding mental health knowledge and attitude of rural health extension workers (HEWs).

- Five districts were included for generalisation to HEWs working in comparable rural areas.

- The data collection tool was only face-validated in the local language.

The focus of the health extension programme (HEP) is disease prevention and health promotion, with limited curative care. $^{7}$ The HEP aims to achieve universal PHC coverage which mainly benefits lowincome households. The second-generation HEP focuses on tackling non-communicable diseases and mental health that are becoming serious problems in the country. ${ }^{8-10}$ Health extension workers (HEWs) are required to complete at least grade 10 . They then receive 1 year of training on basic health promotion, disease prevention, selected curative services and documentation of health information. The second-generation rural HEP includes upgrading HEWs to level 4 community health nurses. ${ }^{711-14}$

Accessibility and affordability of healthcare services, including mental health services in Ethiopia, are inadequate. In response to these unmet needs, Ethiopia has developed the HEP structure in 2003, based on the concept and principles of PHC. ${ }^{14-16}$ The HEWs are the key players in the programme. ${ }^{17} 18$

The HEP was initially designed with 16 health packages, focusing on family health, disease prevention, control, hygiene, environmental sanitation, health education and communication. Additional elements have been added over time. The secondgeneration HEP has 18 packages that include mental health as one component, 
yet there is no report of success of the implementation in areas of mental health. ${ }^{19}$

HEWs are front-line formal health workers, and are the first contact of individuals, families and communities with the national health system. Equipping these workers with mental health skills promotes a more holistic approach to patient care and ensures improved detection and prevention of mental disorders. ${ }^{20} \mathrm{PHC}$ in developing countries continues to rely heavily on paramedical personnel. ${ }^{21}$

Integrating mental healthcare into community care is a fundamental process that enables the largest number of people to gain faster and easier access to mental healthcare services. ${ }^{22}$ It can reduce stigma, improve social integration and improve human resources for mental services. ${ }^{20}$ One of the major challenges of successfully integrating mental health into community health services is the lack of adequate knowledge, attitude and mental health service delivery skills of health service workers in the community. ${ }^{23}$ Studies among PHC workers in Nigeria showed that most of them were poorly enlightened about mental health principles, had poor knowledge, and exhibited negative attitudes towards mentally ill persons. ${ }^{24-26}$

However, there is limited information about the knowledge and attitude of the HEWs regarding mental health problems in the Ethiopian context. The study results are expected to provide baseline information about the current status of the knowledge and attitudes of HEWs regarding mental health problems. We believe that a knowledge and attitude survey of HEWs is necessary, as it will serve as an input for the successful integration of mental health service into HEP.

\section{OBJECTIVES}

This study aimed to assess the level of knowledge and attitude of HEWs towards mental health problems, in Jimma, Ethiopia.

\section{METHODS}

\section{Study design}

A cross-sectional study design was employed.

\section{Study setting}

The study was conducted in the five districts of Jimma Zone in the Oromia region of Ethiopia, namely Seka Chekorsa, Mana, Shebe Senbo, Kersa and Dedo. Jimma Zone is administratively divided into 20 districts and one town administration with 545 Gandas (lowest administrative unit in Oromia region). The total population of the zone was 3209127 in $2017 .{ }^{27}$ There are four primary hospitals, 20 health centres and 117 health posts in the administrative zone. Additionally, there are 36 private and 3 non-governmental organisation clinics, and 65 private rural drug vendors. ${ }^{28}$ One thousand twenty-four HEWs are serving the population in this area. The primary role of the HEWs in the zone is health promotion, disease prevention, and treatment of uncomplicated and non-severe illnesses such as malaria, pneumonia, diarrhoea and malnutrition. The study was conducted from 15 August to 30 August 2020.

\section{Sample size estimation}

The sample size was calculated using a single population proportion formula $\left(\mathrm{n}=(\mathrm{z} \alpha / 2){ }^{2} \mathrm{P}(1 \mathrm{p}) / \mathrm{d}^{2}\right)$. Due to the unavailability of studies reflecting the proportion of HEWs' knowledge and attitude regarding mental health problems, we have used $50 \%$ sample proportion. The other assumptions were $95 \%$ confidence level and $5 \%$ margin of error. Accordingly, $\mathrm{n}=(1.96)^{2} \times 0.5$ $(1-0.5) /(0.05)^{2}=384$. Since the total population of HEWs in the districts was less than 10000 , the correction formula $\mathrm{Nf}=\mathrm{ni} / 1+\mathrm{ni} / \mathrm{n}=384 / 1+384 / 1024=279$ was used. Finally, with the addition of a $10 \%$ non-response rate, the required sample size becomes 307 .

\section{Sampling procedures and participants}

A cross-sectional survey with cluster sampling technique was conducted on HEWs working in the selected districts of the Jimma zone. Out of the 20 districts in the administrative zone, 5 were determined using a simple random sampling lottery technique. All 307 HEWs working in the selected districts were traced and sampled in the study.

\section{Data collection tools and procedures}

Data were collected using a structured, pretested and self-administered questionnaire. The data collection tool has three parts; sociodemographic, knowledge and attitude of the respondents towards mental health and illness. The 30-item questionnaire was prepared to measure the respondents' knowledge, which was developed from the adapted version of the Mental Health Knowledge Schedule (MAKS) Questionnaire ${ }^{29}$ and an extensive literature review. The survey tool has sound reliability and validity across many works of literature. ${ }^{29-33}$ The reliability, Cronbach's $\alpha$ score of the scales in our study was 0.70 . The questions had dichotomous 'Yes' and 'No' choices. The study participants' attitude was assessed by a 25-item attitude scale adapted from the Community Attitude Towards Mentally Ill Questionnaire (CAMI) ${ }^{34}$ The scale is a well-validated and reliable tool. ${ }^{30}{ }^{35-37}$ The reliability, Cronbach's $\alpha$ score of the scales in this study was 0.63 . Respondents were asked to rate each attitude-related question on a 5-point Likert Scale ranging from 1 (strongly disagree), 2 (disagree), 3 (neutral), 4 (agree) to 5 (strongly agree). Permission is freely granted to use the CAMI and MAKS scales for research, educational, academic and professional purposes. The data were initially prepared in English and translated into Afaan Oromo language and back-translated to English to ensure its consistency by blinded language experts. The data were collected through Afaan Oromo and the English 
Table 1 Sociodemographic characteristics of the respondents at Jimma Zone, Oromia, Ethiopia, August 2020

\begin{tabular}{|c|c|c|c|}
\hline Variables & Characteristics & Frequency (n) & Percentage (\%) \\
\hline Sex & Female & 259 & 100 \\
\hline \multirow[t]{3}{*}{ Age, years } & $18-25$ & 62 & 23.9 \\
\hline & $>30$ & 55 & 21.2 \\
\hline & Mean \pm SD & $27.8 \pm 4.0$ & \\
\hline \multirow{2}{*}{ Ethnicity } & Amhara & 16 & 6.2 \\
\hline & Others* & 10 & 3.8 \\
\hline \multirow[t]{3}{*}{ Religion } & Muslim & 180 & 69.5 \\
\hline & Orthodox & 58 & 22.4 \\
\hline & Protestant & 19 & 7.3 \\
\hline \multirow{2}{*}{ Marital status } & Married & 195 & 75.3 \\
\hline & Divorced & 2 & 0.8 \\
\hline \multirow[t]{4}{*}{ Number of HEWs in the health post } & One & 9 & 3.5 \\
\hline & Two & 104 & 40.2 \\
\hline & Three & 122 & 47.1 \\
\hline & Four and above & 24 & 9.3 \\
\hline \multirow[t]{3}{*}{ Monthly salary } & 2000-3500 & 23 & 8.9 \\
\hline & $3501-4500$ & 113 & 43.6 \\
\hline & $4501-6000$ & 93 & 35.9 \\
\hline Year of service & Mean (SD) $7.5 \pm 3.7$ & & \\
\hline
\end{tabular}

*Other ethnicities include Yem and Gurage.

HEW, health extension worker.

version of the questionnaire. The translations were face-validated by two independent external experts in the field. Moreover, the questionnaire was pretested on $5 \%$ of the population in another district to check the impending problems of the data collection tool. Data quality was ensured through adequate sequence generation (randomisation), standardised protocols for data collection and training of study supervisors. One

Table 2 Knowledge of the respondents towards mental health and mental health problems at Jimma Zone, Oromia, Ethiopia, August 2020

\begin{tabular}{llrr}
\hline Variables & Response & Frequency & Percentage \\
\hline Women are less prone to psychiatric disorders & Yes & 204 & 78.8 \\
Children do not suffer from psychiatric problems & Yes & 174 & 67.2 \\
Older people are less prone to mental disorders & Yes & 97 & 37.5 \\
Psychiatric disorders are a kind of medical disorders & Yes & 120 & 46.3 \\
Contact with psychiatric patients lead to strange behaviour & Yes & 158 & 61.0 \\
Recovered psychiatric patients are employed productively & Yes & 204 & 78.8 \\
\hline
\end{tabular}


clinical nurse in each sampled woreda traced the available HEWs and supervised the data collection activities.

\section{Data management and statistical analysis}

The collected data were cleaned, coded, entered into Epi Data V.3.1 and exported to SPSS V.23 for analysis. Descriptive statistics were used to summarise the dependent and independent variables. The negatively worded items were reverse-coded. Cut-offs of the points below and above the median score were taken to calculate respondents' proportion with adequate and inadequate knowledge and favourable and unfavourable attitude. Moreover, analysis of variance (ANOVA) and independent t-tests were carried out to compare the mean difference between knowledge, attitude and categorical variables.

\section{Patient and public involvement}

Patients and/or the public were not involved in the design, or conduct, or reporting, or dissemination plans of this research.

\section{RESULTS}

\section{Sociodemographic characteristics}

From a total of 307 sampled study participants, 259 completed the questionnaire successfully, giving a response rate of $84.4 \%$; unwillingness to participate in the study was the reason for non-participation. The mean (SD) age of the respondents was $27.8 \pm 4.0$ years. All the respondents were female. The majority of the respondents were Oromo (233, 90\%), Muslim (180, $69.5 \%)$ and married $(195,75.3 \%)$. The mean $(\mathrm{SD})$ years of service was $7.5 \pm 3.7$ years, and no missing data in the variable of interest were found (table 1).

\section{Knowledge towards mental health and mental health problems}

More than half of the respondents reported psychiatric disorders are not medical disorders $(139,53.7 \%)$. Similarly, most $(158,61.0 \%)$ described contact with psychiatric patients leads to strange behaviour. More than two-thirds of the participants $(174,67.2 \%)$ reported children do not suffer from psychiatric problems. Likewise, over threequarters $(78.8 \%)$ of the respondents described women are less prone to psychiatric disorders (table 2).

About 219 (84.6\%) of the respondents reported the risk of psychiatric problems increases in people who have a lot of tension. Similarly, nearly two-thirds $(169,65.3 \%)$ of the respondents mentioned drug/substance abuse causes mental illness. Likewise, more than half of the study participants $(139,53.7 \%)$ described mental illness is due to evil spirit possession. Almost all $(240,92.7 \%)$ respondents reported talking or laughing alone as a manifestation of mental illness. Nearly a quarter $(63,24.3 \%)$ of respondents stated witch doctors should manage mental illness. Similarly, $70(27.0 \%)$ reported mental illness could be cured by marriage (tables 3 and 4 ).

The data analysis showed the median score of knowledge was 20, with a minimum and maximum score of 11 and 30, respectively. Categorising the population's proportion with adequate and inadequate knowledge below and above the median score, $122(47.1 \%)$ of

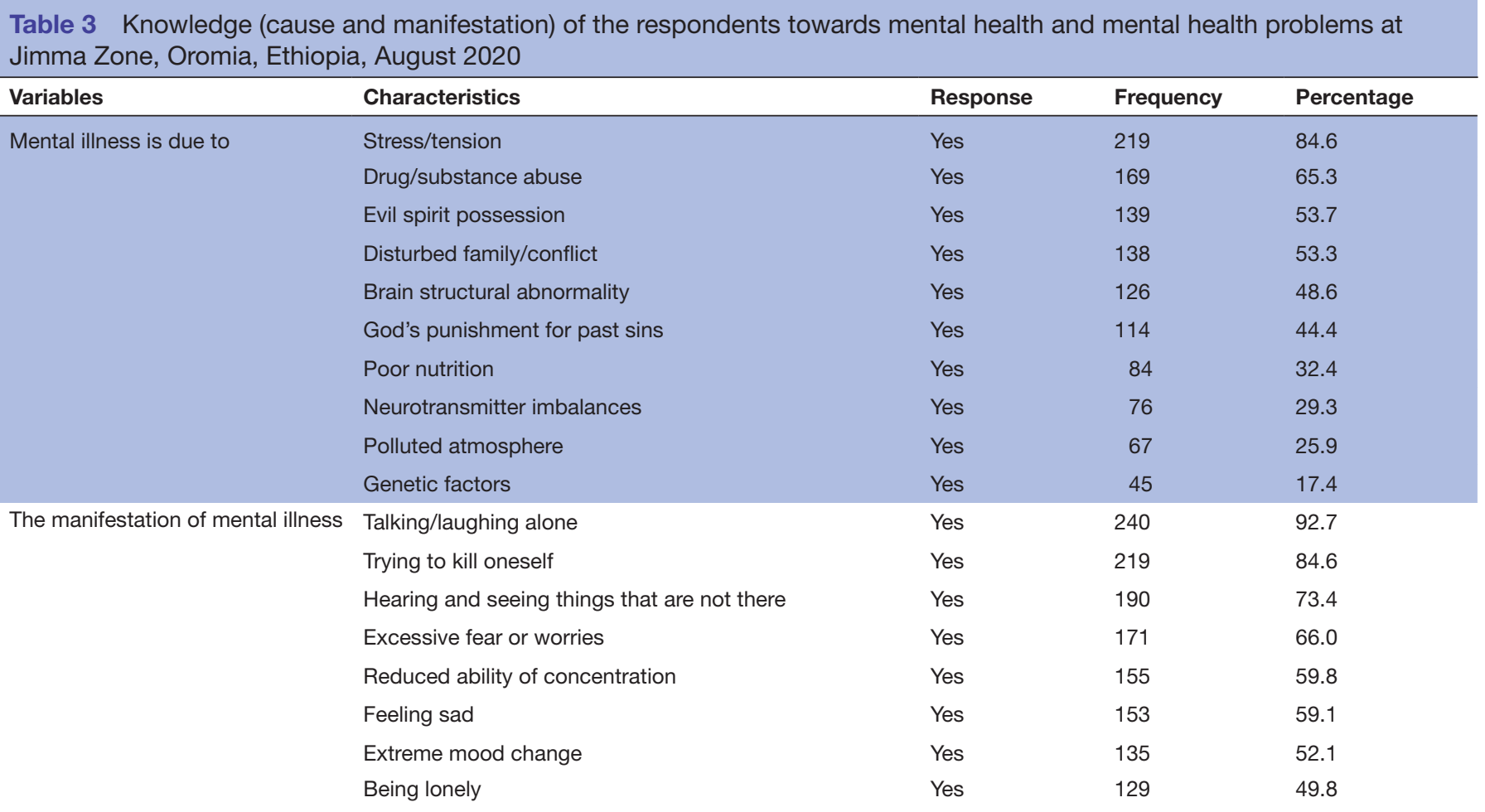


Table 4 Knowledge (management) of the respondents towards mental health and mental health problems at Jimma Zone, Oromia, Ethiopia, August 2020

\begin{tabular}{|c|c|c|c|}
\hline Characteristics & Response & Frequency & Percentage \\
\hline Medication can be an effective treatment for people with mental illnesses & Yes & 241 & 92.3 \\
\hline Mental illness can be managed in a psychiatric hospital & Yes & 239 & 92.3 \\
\hline Mental illness can be successfully managed at home by families & Yes & 102 & 39.4 \\
\hline Witch doctors should manage mental illness & Yes & 63 & 24.3 \\
\hline
\end{tabular}

the respondents had insufficient knowledge regarding mental health problems.

\section{Attitude towards mental health and mental health problems}

More than three-quarters $(207,80 \%)$ of the study respondents concurred mentally ill patients need the same kind of control as a young child. Above one-third, (100, 38.6\%) of them reported mentally ill patients are a burden on society. About two-thirds (157, 60.6\%) of the respondents reported people with mental illness are dangerous. Moreover, nearly two-thirds $(165,63.7 \%)$ reported that mentally ill persons should be denied their rights. Likewise, more than a third of the respondents $(96,37.1 \%)$ mentioned it is best to avoid anyone who has mental health problems (tables 5 and 6 ).

Data analysis showed the median score of attitudes was $83 \pm 8.11$ with a score range of 62 and 107, respectively. Categorising the percentage of the population with favourable and unfavourable attitudes below and above the median score, $(125,48.3 \%)$ of the respondents had an unfavourable attitude

Knowledge mean difference of the respondents (t-test)

Independent t-test analysis showed that there is a significant difference between those who have additional income other than their salary and their counterparts;

Table 5 The attitude (CAMI Scale authoritarianism and benevolence) of the respondents towards mental health and mental health problems at Jimma Zone, Oromia, Ethiopia, August 2020

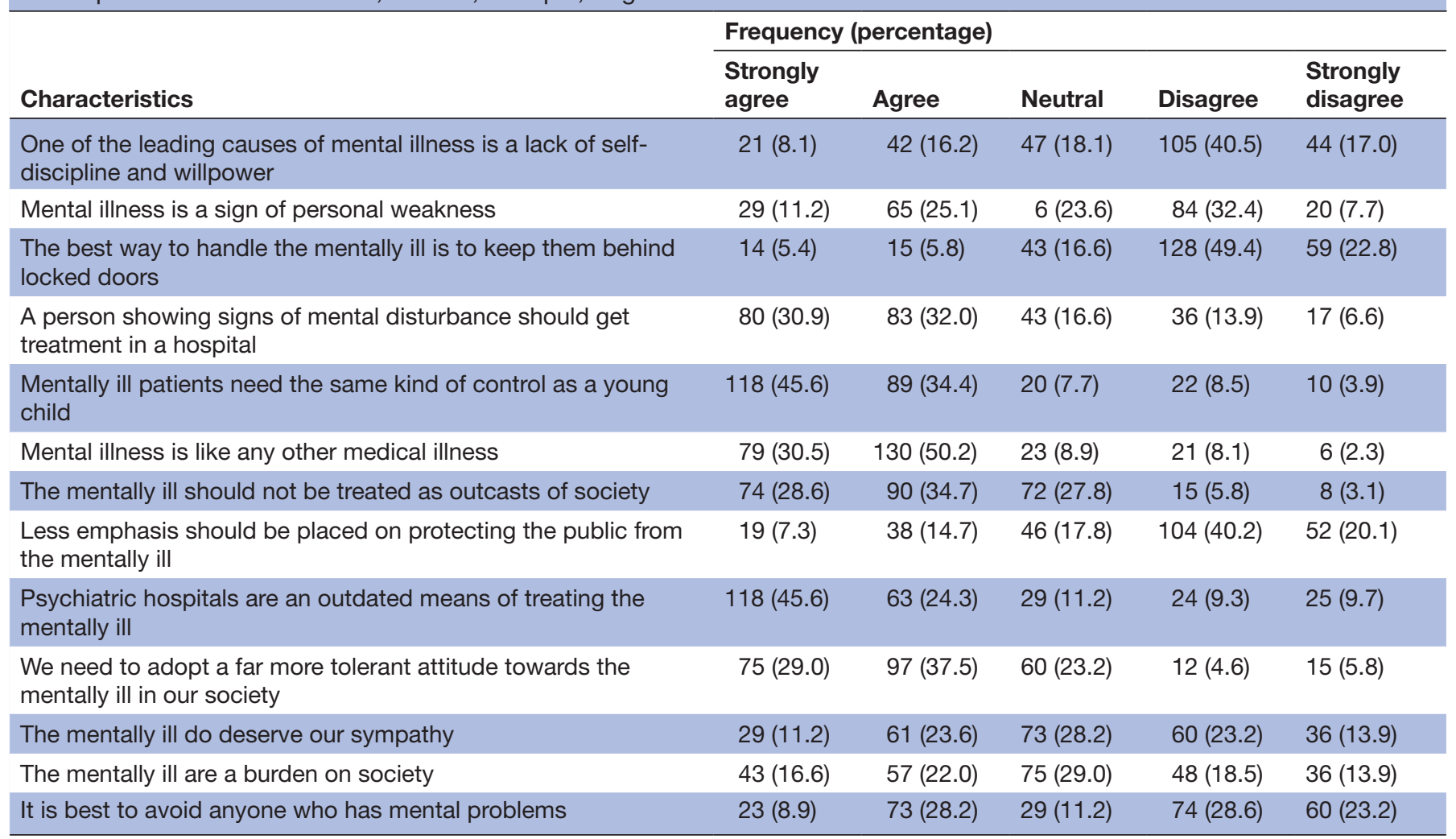

CAMI, Community Attitude Towards Mentally III. 
Table 6 The attitude (CAMI Scale social restrictiveness and community mental health ideology) of the respondents towards mental health and mental health problems at Jimma Zone, Oromia, Ethiopia, August 2020

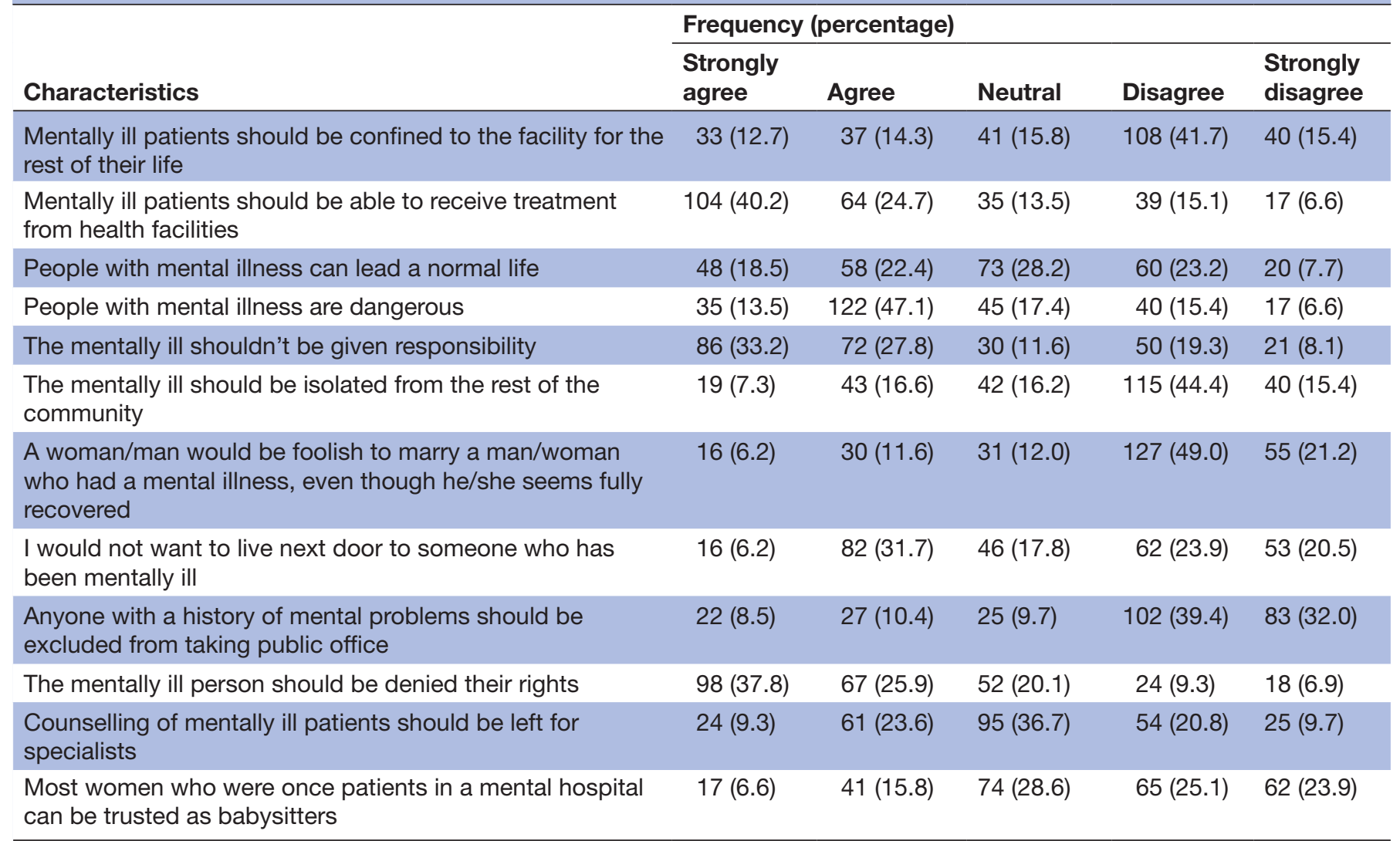

CAMI, Community Attitude Towards Mentally III.

this value was statistically significant at $95 \% \mathrm{CI}-2.78$ to $-0.68, \mathrm{t}$ value of -3.24 and a value of $\mathrm{p}<0.001$ (table 7 ).

\section{Attitude mean difference of the respondents (t-test)}

There was a statistically significant mean difference regarding the mental health attitude of the respondents among those who had adequate and inadequate mental health knowledge. This was statistically significant at $95 \%$ CI 1.89 to 7.18 , t-value of 3.87 and value of $\mathrm{p}<0.001$ (table 7 ).

\section{Knowledge mean difference of the respondents (F-test)}

One-way ANOVA showed there was a statistically significant mean difference between those who worked 1-5 years, 6-10 years and more than 10 years $(p=0.002)$ (table 7).

\section{Attitude mean difference of the respondents (F-test)}

There was a statistically significant mean difference between the respondents' attitudes among those who worked $6-10$ years and more than 10 years $(\mathrm{p}=0.023)$ (table 7 ).

\section{DISCUSSION}

This study aimed to assess the knowledge and attitude of HEWs regarding mental health and mental health problems.
In this study, nearly half of the respondents had inadequate knowledge regarding mental health problems. Consistent findings were reported from the studies among health extension professionals in Addis Ababa and West Amhara. ${ }^{18} 38$ Similarly, a study in rural Igbo land Nigeria showed $41 \%$ of the respondents had inadequate knowledge. ${ }^{26}$ The study in Saudi Arabia among non-psychiatric health professionals showed nearly a third of the participants lacked adequate knowledge regarding mental illnesses. ${ }^{39}$ On the contrary, the study among nursing staff in Jimma Zone, south-west Ethiopia, revealed about $89 \%$ of the respondents were knowledgeable about mental health problems. ${ }^{40}$ A low level of mental health literacy could be one of the causes of inadequate mental health knowledge. Moreover, the norms, beliefs, traditions and culture in the study setting could also contribute to the existing low knowledge of mental health problems.

In this study, more than half of the respondents mentioned that psychiatric disorders are not a kind of medical disorder. In contrast to this, the study done in Rwanda showed more than three-quarters of the respondents reported mental disorder as an illness like any other. ${ }^{41}$ Similarly, the study in Nigeria showed that more than half of the respondents agreed mental illness is an illness like any other. ${ }^{42}$ The discrepancies among these studies might be explained by the differences in mental 
Table 7 Test statistics ( $\mathrm{t} / \mathrm{F}$-tests) of knowledge and attitude mean difference of the respondents

\begin{tabular}{|c|c|c|c|c|}
\hline Variables & Response category & Mean (SD) & Test statistics (t/F-test) & $P$ value \\
\hline \multicolumn{5}{|l|}{ Knowledge mean difference } \\
\hline Income & No additional income & $17.54(2.79)$ & $t_{257}=-3.24$ & 0.001 \\
\hline \multicolumn{5}{|c|}{ Attitude mean difference of the respondents } \\
\hline Marital status & Never married & $78.91(7.95)$ & $t_{257}=-2.22$ & 0.02 \\
\hline \multirow[t]{2}{*}{ Knowledge of mental health } & Adequate Knowledge & $82.99(8.87)$ & $t_{257}=3.87$ & $<0.001$ \\
\hline & Inadequate knowledge & & & \\
\hline \multicolumn{5}{|l|}{ Knowledge mean difference } \\
\hline \multirow[t]{2}{*}{ Monthly salary } & $2000-3500$ & $18.9(4.8)$ & $F_{3}=3.84$ & 0.01 \\
\hline & $3501-4500$ & $19.6(4.0)$ & & \\
\hline \multirow[t]{3}{*}{ Service year } & $1-5$ years & $18.0(3.4)$ & $F_{2}=6.59$ & 0.002 \\
\hline & $6-10$ years & $18.5(3.6)$ & & \\
\hline & Over 10 years & $18.8(3.7)$ & & \\
\hline \multicolumn{5}{|l|}{ Attitude mean difference } \\
\hline \multirow[t]{4}{*}{ Monthly salary } & 2000-3500 & $77.2(10.2)$ & $F_{3}=2.89$ & 0.036 \\
\hline & $3501-4500$ & $82.3(8.8)$ & & \\
\hline & $4501-6000$ & $80.3(7.0)$ & & \\
\hline & 6001 and above & $80.3(6.4)$ & & \\
\hline Service year & $1-5$ years & $80.3(6.9)$ & $F_{2}=2.89$ & 0.023 \\
\hline
\end{tabular}

health literacy status and the widespread misconception of mental health problems attributed to religious and traditional factors across different cultures.

Stress, brain structural abnormality and evil spirit possession were mentioned as the most common causes of mental illness in our study. Similar findings were reported from the study among health extension professionals in Addis Ababa, Ethiopia. ${ }^{18}$ Likewise, a study on nursing staff in Jimma, Ethiopia, showed biochemical disturbance, poverty, physical illness, heredity and evil spirits were implicated as causes of mental health problems. ${ }^{40}$ Similarly, a study among nurses in Lagos, Nigeria, showed the most frequently mentioned aetiology of mental illness was genetic inheritance, misuse of drugs and alcohol, and persistent stress. ${ }^{43}$ A consistent report was also found from the studies in Nepal among nursing staff, which revealed the majority had shown their knowledge about the causes of mental illness as genetic or inherited and biochemical disturbances. ${ }^{44}$ Contrary to the above findings, a scoping review in Nigeria showed that the most common knowledge of mental illness causes was supernatural causes. ${ }^{46}$ Likewise, a study in rural Igboland, Nigeria, showed half of the respondents mentioned evil spirit possession as the cause of mental illness. ${ }^{26}$ The knowledge regarding the cause of mental health problems is different in different study areas. This reflects the mental health literacy status, the availability of mental health promotion activities in the areas, and the cultural and traditional mental health explanation dominances in different countries.

Our study findings reveal that nearly half of the participants had an unfavourable attitude regarding mental health problems. Similarly, a study in Saudi Arabia showed 44.7\% of the respondents had an unfavourable attitude towards mental illnesses. ${ }^{39}$ Studies in Addis Ababa, ${ }^{48}{ }^{48}$ China $^{49}$ and Kuwait $^{50}$ found most PHC providers still held a pessimistic attitude towards mental illness. This finding is much lower than in the study among health extension professionals in Addis Ababa, Ethiopia, which revealed that $93.4 \%$ of health extension professionals had a negative attitude towards mental illness. ${ }^{18}$ Similarly, studies in Nigeria showed nearly three-quarters of the respondents expressed a generally negative attitude towards mentally ill patients. ${ }^{21}{ }^{26}$ Mental health problems are commonly explained with the community prevailing traditional and religious perspectives. Community health workers misconception due to misunderstanding of the nature of the problems is a reflection of the community poor knowledge and attitude towards mental 
health problems. As HEWs do not receive any mental health training, it could reflect the attitude gap in this group.

In the current study, nearly half of the respondents reported that people with mental illness are dangerous. A similar finding was reported among rural PHC providers in China. ${ }^{49}$ However, in Rwanda where more than two-thirds of the participants and more than half of the respondents in Nigeria opined that mentally ill are far less dangerous than most persons would think. ${ }^{41}{ }^{42}$ This could be because of the media's inaccurate and exaggerated portrayal of mentally ill people as dangerous criminals and observing untreated patients with severe mental illness in the community while wandering nude and violent could contribute to the negative attitudes of the respondents.

This study's finding has shown more than a third of the respondents described it is best to avoid anyone who has mental health problems. Consistent findings were reported from studies in Nigeria. ${ }^{42}{ }^{46}$ This was unlike most respondents in Nepal, who were ready to work together and chat with mentally ill individuals. ${ }^{445}$ The discrepancies between these studies could be explained by mental health literacy, the experience with patients, the fear of mental health problems being contagious, and the availability of mental health services.

Nearly a quarter of participants in this study stated that mental illness should be managed by witch doctors, consistent with the outcome of studies in Addis Ababa, Ethiopia and Nigeria, eliciting preference for religious and traditional treatments. ${ }^{26} 4647$ Our study has found many of the respondents reported religious and traditional causes for mental health problems. This belief could contribute to the traditional treatment preference for mental health problems.

The strength of this research could be that the study included representative samples of rural HEWs, so the study can be generalised to rural HEWs in Jimma Zone and similar areas in Ethiopia.

However, the investigation has some limitations. First, we have included only five districts in Jimma Zone, hence it cannot be generalised to other areas with varying contexts. Second, the adapted version of the tools was only facevalidated, though checked for reliability with Cronbach's $\alpha$. Third, this study included a small number of participants. A further limitation of the study could be that we planned to include 307 samples; however, data were collected from only 259 respondents because some sample study participants were unwilling to participate in the study. Finally, this study did not use qualitative methods to enrich the quantitative findings.

\section{CONCLUSIONS/INTERPRETATION}

The findings of this study showed a significant proportion of HEWs have inadequate knowledge and an unfavourable attitude towards mental health problems. HEWs are front-line health cadres; they are the first contact of individuals, families and the community. So equipping these health workers with mental health skills promotes a more holistic approach to patient care; it also ensures improved early detection and prevention of mental disorders. Therefore short-term and long-term training is required to integrate mental health into the HEW programme successfully.

\section{GENERALISABILITY}

The study can be generalised to rural HEWs in Jimma Zone and similar areas in Ethiopia.

\section{Author affiliations}

${ }^{1}$ Department of Psychiatry, Jimma University, Jimma, Ethiopia

${ }^{2}$ Department of Health, Behavior and Society, Jimma University, Jimma, Ethiopia

${ }^{3}$ School of Nursing and Midwifery, Jimma University, Jimma, Ethiopia

${ }^{4}$ Department of Health Policy and Management, Jimma University, Jimma, Ethiopia

${ }^{5}$ Department of Biostatistics and Epidemiology, Jimma University, Jimma, Ethiopia

${ }^{6}$ Department of Environmental Health Sciences and Technology, Jimma University, Jimma, Ethiopia

Acknowledgements The authors thank Jimma University for financial support and the study participants for providing study information.

Contributors YT, KY, LA, GA, ZB, GTT, SA and MG carried out the study, participated in tool development and coordinated the data collection activity. YT has done the statistical analysis and drafting, and edited the manuscript. KY, ZB, GTT, YT and SA reviewed the paper and the manuscript. All the authors read and approved the final manuscript. YT is guarantor of this study.

Funding This work was supported by Jimma University, grant number IHRPGD/594/2019. The funder has no role in designing the study, conducting analysis and interpreting the results.

Competing interests None declared.

\section{Patient consent for publication Not applicable.}

Ethics approval The study was reviewed and approved by the Institutional Review Board (IRB) of Jimma University (IHRPGD/584/2019). An official letter of support was obtained from the Oromia Health Bureau and the Jimma zone health bureau. A subsequent support letter was sought from each selected district health office before the commencement of data collection. Respondents were briefed on the study objectives and were assured of the anonymity of their participation. The study participation was wholly voluntary and written informed consent was obtained from each respondent.

Provenance and peer review Not commissioned; externally peer reviewed.

Data availability statement Data are available upon reasonable request.

Open access This is an open access article distributed in accordance with the Creative Commons Attribution Non Commercial (CC BY-NC 4.0) license, which permits others to distribute, remix, adapt, build upon this work non-commercially, and license their derivative works on different terms, provided the original work is properly cited, appropriate credit is given, any changes made indicated, and the use is non-commercial. See: http://creativecommons.org/licenses/by-nc/4.0/.

\section{ORCID iDs}

Yonas Tesfaye http://orcid.org/0000-0002-6707-9900

Kiddus Yitbarek http://orcid.org/0000-0001-8662-7434

\section{REFERENCES}

1 Ndetei DM, Khasakhala LI, Mutiso V, et al. Knowledge, attitude and practice (KAP) of mental illness among staff in general medical facilities in Kenya: practice and policy implications. Afr J Psychiatry 2011;14:225-35.

2 Mendenhall E, De Silva MJ, Hanlon C, et al. Acceptability and feasibility of using non-specialist health workers to deliver mental health care: stakeholder perceptions from the prime district sites in Ethiopia, India, Nepal, South Africa, and Uganda. Soc Sci Med 2014;118:33-42.

3 World Health Organization. Global burden of mental disorders and the need for a comprehensive, coordinated response from health and social sectors at the country level, 2012: 1-6. 
4 Abera M, Tesfaye M, Belachew T, et al. Perceived challenges and opportunities arising from integration of mental health into primary care: a cross-sectional survey of primary health care workers in south-west Ethiopia. BMC Health Serv Res 2014;14:113.

5 Gureje O, Lasebikan VO, Ephraim-Oluwanuga O, et al. Community study of knowledge of and attitude to mental illness in Nigeria. $\mathrm{Br} J$ Psychiatry 2005;186:436-41.

6 Salve H, Goswami K, Sagar R, et al. Perception and Attitude towards Mental Illness in an Urban Community in South Delhi - A Community Based Study. Indian J Psychol Med 2013;35:154-8.

7 Federal Ministry of Health Ethiopia. Second generation health extension program, 2003

8 Ethiopian Federal Ministry of Health. 2nd Generation Health Extension Program to be implemented in 4,500 Clinics [Internet]. Available: http://www.moh.gov.et/ejcc/en/node/177

9 Admasu K, Balcha T, Ghebreyesus TA. Pro-poor pathway towards universal health coverage: lessons from Ethiopia. J Glob Health 2016;6:10305

10 Balcha T, Getahun H, Admasu K. Local innovations and country ownership for sustainable development. Bull World Health Organ 2015;93:164483.

11 Damtew ZA, Lemma S, Zulliger R. Ethiopia's Health Extension Program. Health for the People: National Community Health Worker Programs from Afghanistan to Zimbabwe, 2020: 75-86.

12 Ethiopian Federal Ministry of Health. Health sector strategic plan III. Government of Uganda, 2005.

13 Ethiopian Federal Ministry of Health. Health sector transformation plan.

14 Wang H, Tesfaye R, Ramana GN V. Ethiopia health extension program, 2016.

15 FMOH. National Mental Health Strategy 2012/13 - 2015/16. Fed Democr Repub Ethiop Minist Heal, 2013.

16 International D, Lookout S, Nation F. Best Practices in Implementing Community Health Worker Programs : Case Studies from Around the Globe - A Programmatic Report 2016.

17 Workie N, Ramana W, Gandham N. The health extension program in Ethiopia (Washington, DC: world bank, 2013). UNICO Stud Ser 2013.

18 Ahmed E, Merga H, Alemseged F. Knowledge, attitude, and practice towards mental illness service provision and associated factors among health extension professionals in Addis Ababa, Ethiopia. Int $J$ Ment Health Syst 2019;13:5.

19 Evaluation of the second-generation health extension programme's $S$ impact on health post capacity to prevent, prepare for and respond to shocks in selected areas of Ethiopia research plan 2020.

$20 \mathrm{WHO}($ World Health Organization). Integrating mental health services into primary health care, 2001: 1-7.

21 Abiodun OA. Knowledge and attitude concerning mental health of primary health care workers in Nigeria. Int $J$ Soc Psychiatry 1991;37:113-20.

22 Budosan B. Mental health training of primary health care workers: case reports from Sri Lanka, Pakistan, and Jordan. Intervention 2011;9:125-36.

23 Adebowale T, Onofa Lucky U, Gater R. Evaluation of a mental health training course for primary health care workers. J Psychiatry 2014;17:14-25

24 Ogunlesi AO, Adelekan ML. Nigerian primary health care workers: a pilot survey on attitude to mental health. Bull. R. Coll. Psychiatr. 1988;12:441-3.

25 Abiodun OA. A study of mental morbidity among primary care patients in Nigeria. Compr Psychiatry 1993;34:10-13.

26 OECEMN A. The concept and attitudes of primary health care workers towards mental illness in rural Igbo land of Nigeria. J Coll Med 2006;11:125-9.

27 Federal Democratic Republic of Ethiopia central statistical agency population projection of Ethiopia for all regions at Wereda level from $2014-20172013$

28 Abajebel S, Jira C, Beyene W. Utilization of health information system at district level in jimma zone oromia regional state, South West Ethiopia. Ethiop J Health Sci 2011;21:65-76.
29 Thornicroft PG. Mental Health Knowledge Schedule MAKS [Internet], 2009. Available: http://citeseerx.ist.psu.edu/viewdoc/download?doi= 10.1.1.468.2785\&rep=rep1\&type=pdf

30 Abi Doumit C, Haddad C, Sacre H, et al. Knowledge, attitude and behaviors towards patients with mental illness: results from a national Lebanese study. PLoS One 2019;14:e0222172.

31 Henderson C, Evans-Lacko S, Thornicroft G. Help-Seeking, and public health programs. Am J Public Health 2013;103:777-80.

32 Wong PWC, Arat G, Ambrose MR. Evaluation of a mental health course for stigma reduction : A pilot study Evaluation of a mental health course for stigma reduction: A pilot study. Cogent Psychol 2019;6:1-12.

33 Evans-Lacko S, Little K, Meltzer H, et al. Development and psychometric properties of the mental health knowledge schedule. Can J Psychiatry 2010;55:440-8.

34 Michael J, Dear SMT. Community attitudes toward the mentally ill questionnaire. Hamilton, Ontario, Canada: Dep Geogr McMaster Univ, 1979.

35 Taylor SM, Dear MJ. Scaling community attitudes toward the mentally ill. Schizophr Bull 1981;7:225-40.

36 Mehta N, Kassam A, Leese M, et al. Public attitudes towards people with mental illness in England and Scotland, 1994-2003. Br J Psychiatry 2009;194:278-84.

37 Abolfotouh MA, Almutairi AF, Almutairi Z, et al. Attitudes toward mental illness, mentally ill persons, and help-seeking among the Saudi public and sociodemographic correlates. Psychol Res Behav Manag 2019;12:45-54

38 Tadege TZ. Knowledge, attitude, practice, and associated factors of health extension professionals with regard to mental illness in West Amhara, Ethiopia. Anatol J Fam Med 2020;2:68-72.

39 AlSalem M, Alamri R, Hejazi S. Nonpsychiatric healthcare professionals' attitudes toward patients with mental illnesses in Makkah City, Saudi Arabia: a cross-sectional study. Neuropsychiatr Dis Treat 2020;16:341-8.

40 Amare D. Assessment of knowledge, attitude, and practice of nursing staff towards mental health problems in Jimma zone, southwestern Ethiopia. Ethiop J Health Sci 2005;15:199-2006.

41 Baziga V. Nurses Stigmatising attitudes towards persons with a mental disorder; a potential barrier of integration of mental health services within urban health centres in a selected district hospital in Rwanda. JOJNHC 2017;3:1-8.

42 Ubaka CM, Chikezie CM, Amorha KC, et al. Health professionals stigma towards the psychiatric ill in Nigeria. Ethiop $\mathrm{J} \mathrm{Health} \mathrm{Sci}$ 2018;28:483-94.

43 Coker A, Oo C AA, Kanmodi K. Nurses' knowledge and attitudes towards the mentally ill in Lagos, south-western Nigeria. Int $J$ Adv Community Med 2018;1:15-21.

44 Shyangwa PM, KSKBPK SS. Knowledge and attitude about mental illness. J Nepal Med Assoc 2003;42:27-31.

45 Gurung G. Knowledge and attitude of nurses regarding mental illness. J Chitwan Med Coll 2014;4:40-3.

46 Okpalauwaekwe U, Mela M, Oji C. Knowledge of and attitude to mental illnesses in Nigeria: a scoping review. Integr J Glob Heal 2017;1:1-14.

47 Mariam MG, A B. Knowledge, attitude and factors associated with mental illness among nurses working in public hospitals, Addis Ababa, Ethiopia. J Ment Disord Treat 2016;2.

48 Sahile Y, Yitayih S, Yeshanew B, et al. Primary health care nurses attitude towards people with severe mental disorders in Addis Ababa, Ethiopia: a cross sectional study. Int J Ment Health Syst 2019;13:1-8.

49 Ma Z, Huang H, Nie G, et al. Attitude towards mental illness among primary healthcare providers: a community-based study in rural China. Biomed Res Int 2018;2018:8715272.

50 Al-Awadhi A, Atawneh F, Alalyan MZY, et al. Nurses' attitude towards patients with mental illness in a general Hospital in Kuwait. Saudi J Med Med Sci 2017;5:31. 